\title{
Organic electrochemistry: basics and applications
}

\begin{abstract}
Organic electrochemistry is the use of electrical current through a reaction to activate organic molecules by means of the addition or removal of electrons. It possesses a number of advantages such as simplicity of reaction and availability of synthetic materials. The former controls electron energy directly via over potential, and reagents only include electrons and protons. The latter includes umpolung chemistry, predictible and tolerable functional groups. As an emerging-market push for "Green Chemistry", organic electrochemistry has high atom economy and low waste. Analytical method is a practical tool to predict reactivity and applicable in metal mediated reactions. To pay sufficient attention for organic electrochemistry, basics and applications of organic electrochemistry will be discussed in this chapter. To introduce organic electrochemistry, the historical developments and pioneers of organic electrochemistry were listed. The progress in organic electrochemistry with its advantages, mechanisms and applications were discussed. In conclusion, more attention was attracted to organic electrochemistry from industry and research centers because electrochemical processes can reduce pollutions and make an eco-friendly environment.
\end{abstract}

Keywords: organic, organic compound, electrochemistry, organic electrochemistry
Volume 3 Issue 3 - 2017

Ozge Surucu, Serdar Abaci

Department of Chemistry, Hacettepe University, Turkey

Correspondence: Serdar Abaci, Department of Chemistry, Hacettepe University, 06800 Ankara, Turkey, Tel +90 312297 6080, Fax +90312299 2163, Email sabaci@hacettepe.edu.tr

Received: September 08, 2017| Published: October 13, 2017

\section{Introduction}

Organic electrochemistry is related to the oxidation and reduction of organic molecules at electrodes. Electrochemistry of organic compounds has been built in twentieth century with the studies in nineteenth century. These studies were given in Table 1 as historical listing in order. Although we are eldership according to 200 years ago, investigations of organic electrochemical processes had not be done until the establishment of research area based on the use of electricity in organic synthesis by Faraday ${ }^{1} \&$ Kolbe's ${ }^{2}$ own rights. Towards the ends of nineteenth century, researchers such as Tafel and Haber

Table I Historical progress of organic electrochemistry

\begin{tabular}{lll}
\hline Discovery & Explorer & References \\
\hline Electroorganic synthetic transformation & Faraday and Kolbe & 1,2 \\
Organic electrode processes & Tafel and Haber & 3 \\
Polarography at dropping mercury electrode & Heyrovsky & 4 \\
Polarographic research & Lingane, Kolthoff, Laitenen & 5,6 \\
Potentiostat marking computer era & Hickling & 7 \\
\hline
\end{tabular}

A number of studies reported before World War II had been carried out in aqueous electrolyte solutions, but attention had focused on applications of anhydrous solvents from the mid of 1950s. In this way, detections of primary intermediates typically radical anions, cations and their reactions could be performed. Applications of techniques related to cyclic voltammetry published in 1960s and 1970s had resulted in illumination of kinetics and mechanisms of organic electrochemical processes. ${ }^{8}$ Organic electrochemistry had undergone a revolution after 1960s. New electroanalytical methods enabled an effective illumination of electrochemical reaction mechanisms as a characteristic of the period. Another developments have been obtained by the entry of indirect electrolysis using organic and organometallic mediators and increasing demand for electrochemistry of bio-organic by organic electrochemistry in recent years.

\section{Discussion}

had significantly contributed to informations about organic electrode processes. ${ }^{3}$ Applications of electrolysis carried out by means of organic compounds had continued in the first half of twentieth century. As a result of this progress, new electrochemical techniques had advanced due to the studies of electrode processes including polarography at dropping mercury electrode discovered by Heyrovsky at the beginning of $1920 \mathrm{~s} .{ }^{4}$ Another important contributions to polarographic research had been made by Lingane et al., ${ }^{5}$ Laitinen. ${ }^{6}$ In the following years, Hickling's potentiostat had led to computer era as an experimental tool for control purposes. ${ }^{7}$ Towards World War II, the studies on organic electrochemistry changed into more solvent-based clean environment.

systems. At the same time, novel industrial applications have arised

Organic materials which are both semi-conducting and conducting molecules or polymers have excellent electronic properties in many devices. ${ }^{9}$ Organic electrochemistry commonly consists of anodic oxidation and cathodic reduction. ${ }^{10}$ In anodic oxidation, electron is removed from substrate as a nucleophile and generally highly reactive intermediates are obtained. Electroauxilaries as functional groups are introduced to promote electron transfer in a more selective manner. Electroauxilaries are non-solvent nucleophiles and give selective formation of a single product in higher yield with less energy. 
Anodic oxidation is applicable for complex molecule synthesis and stepwise reactions due to selective oxidation. Substrate reactions can be controlled precisely using electroauxiliaries and progress in enantioselective reactions is made. In cathodic reduction, electron is added to substrate as an electrophile. In this system, oxygen must be isolated and electroreductive reactions occur. Complementary cyclizations can be obtained using umpolung chemistry, alcohol can be reduced easily without use of hyride and incorporation of deuterium is possible.

"Holy Grail" of organic electrochemistry is paired electrosynthesis. However, its use in industry is restricted by mechanics of process, engineering problem and set up costs. Nevertheless, application of organic electrochemistry contains moderate reaction conditions such as choice of solvent, operation voltage, temperature, air humidity and high tolerance for functional groups including halogens, azo compounds, salts etc. Organic materials can be dissolved in most of the common solvents, so they are compatible with printers and other electronic devices. ${ }^{11}$ At the same time, organic electronics can be applied on various surfaces such as papers, plastic foils and metals. A lot of application areas including transistors, photo-diodes, solar cells, light-emitting diodes and lasers are put into practice by means of organic materials. Another unique feature of organic materials is ions and electrons which supply transportation of charges, and such an ability is important in chemical sensors and ion-electronics. ${ }^{12}$ As an intrinsically practical technique, organic electrochemistry is a good way in setting of process chemistry because greenness of the reactions is created by the use of electric current instead of stoichiometric redox species and the scaling up reactions easily. ${ }^{13}$

Organic electrochemistry has expanded into a range of industry fields such as hydrodimerization of acrylonitrile (Monsanto), oxidation of methyl aromatics (BASF) and methoxylation (Otsuka) processes ${ }^{14}$ from the early beginnings of Faraday ${ }^{1} \&$ Kolbe $^{2} \&$ Haber ${ }^{15}$ reactions. Organic synthesis using electrochemical techniques is on an increasing demand since a Japan group has organized "Electroorganic Chemistry" in 1980 and then the subject has been combined with various areas of science and technology. In future, organic electrosynthesis will be used to keep toxic and dangerous redox reagents out and reduce energy comsumption, and stand out among green methodologies to produce compatible processes in developing socities. ${ }^{16}$ New developments in organic electrochemistry focus on the electrode interface controlling electron-transfer reaction fields and establishing a connection with biochemistry and coordination chemistry. Therefore, the field of organic electrochemistry is enlarging day by day because of a huge number of fabrication, construction and application possibilities of organic electrochemistry using various electrode materials.

\section{Conclusion}

As it is known, there is a large literature history about organic electrochemistry beginning from the nineteenth century. In this mini review, only basic concepts and applications of organic electrochemistry are mentioned and such a major topic can not be restricted to a few papers. At time when organic materials capture all of our lifes, the activation of such materials using simple, economic and eco-friendly electrochemical techniques become more of an issue. Therefore, more attention must be given for organic electrochemistry and this review will contribute even if just a bit for future studies.

\section{Acknowledgements}

None

\section{Conflict of interest}

The author declares no conflict of interest.

\section{References}

1. Faraday M. Experimental researches in electricity. Phil Trans $R$ Soc Lond. 1834;124:77-122.

2. Kolbe H. Untersuchungen über die Elektrolyse organischer Verbindungen Justus Liebigs Ann Chem. 1849;69:257-372.

3. Leibzig B. Über stufenweise Reduktion des Nitrobenzols mit begsentzem Kathodenpotential. Z Elektrochem. 1898;4:506-514.

4. Heyrovsky J, Shikata M. Researches with the dropping mercury cathode. Rec Trav Chim Pays Bas. 1925;44(6):496-499.

5. Kolthoff IM, Lingane JJ. Polarography. USA: Interscience; 1949.

6. Laitinen HA, Wawzonek S. The reduction of unsaturated hydrocarbons at the dropping mercury electrode. i. phenyl substituted olefins and acetylenes. J Am Chem Soc. 1942;64(8):1765-1768.

7. Hickling A. Studies in electrode polarisation. Part IV.-The automatic control of the potential of a working electrode. Trans Faraday Soc. 1942;38:27-33.

8. Baizer MM. Organic Electrochemistry. An Introduction and a Guide. In: Herausgeg, et al. editors. USA: Marcel Dekker Inc; 1973;46(22):968.

9. Nilsson D, Kugler T, Svensson PO, et al. An all-organic sensortransistor based on a novel electrochemical transducer concept printed electorchemical sensors on paper. Sens Act B Chem. 2002;86(2-3):193197

10. Sperry JB, Wright DL. The application of cathodic reductions and anodic oxidations in the synthesis of complex molecules. Chem Soc Rev. 2006;35(7):605-621.

11. Sirringhaus H, Kawase T, Friend RH, et al. High-resolution inkjet printing of all-polymer transistor circuits. Science. 2000;290(5499):2123-2126.

12. Nilsson $\mathrm{D}$, Chen $\mathrm{M}$, Kugler $\mathrm{T}$, et al. Bi-stable and dynamic current modulation in electro-chemical organic transistors. Adv Mater. 2002;14(1):51-54.

13. Horn EJ, Rosen BR, Baran PS. Synthetic Organic Electrochemistry: An Enabling and Innately Sustainable Method. ACS Cent Sci. 2016;2(5):302-308.

14. Pletcher D, Walsh FC. Industrial Electrochemistry. Blackie Academic \& Professional, Scotland: Springer; 1993. 672 p.

15. Haber F, Schmidt C. Ueber den Reductions vorgang bei der elektrischen Reduktion des Nitrobenzols. Z Phys Chem. 1990;32:271-287.

16. Frontana-Uribe BA, Little RD, Ibanez JG, et al. Organic electrosynthesis: a promising green methodology in organic chemistry. Green Chem. 2010;12:2099-2119. 